\title{
The Influence of YouTube Beauty Vloggers on Indonesian Consumers' Purchase Intention of Local Cosmetic Products
}

\author{
Jui-Lung Chen $^{1} \&$ Apritika Dermawan ${ }^{1}$ \\ ${ }^{1}$ Department of Business Administration, National Chin-Yi University of Technology, Taiwan, R.O.C. \\ Correspondence: Jui-Lung Chen, Department of Business Administration, National Chin-Yi University of \\ Technology, No.57, Sec. 2, Zhongshan Rd., Taiping Dist., Taichung 41170, Taiwan, R.O.C. E-mail: \\ leonchen@ncut.edu.tw
}

Received: January 3, 2020

Accepted: March 19, 2020

Online Published: April 15, 2020

doi:10.5539/ijbm.v15n5p100

URL: https://doi.org/10.5539/ijbm.v15n5p100

\begin{abstract}
Social media are web-based technology and social platform that involve social, personal and technological factors, which have triggered the development and evolution of website-based communities. Moreover, relevant web-based applications have also become the mainstream media for value creation and information exchange. The proliferation, convenience, and immediacy of social media have attracted many enterprises to adopt social media as a marketing tool. Among them, Electronic Word-of-Mouth (E-WoM), used mostly by vloggers (video bloggers), enables its users to review products and express their opinions on social media. Therefore, E-WoM has gradually become an important source of information for consumers, which influences their purchasing decisions. YouTube, a video sharing platform affiliated with Google, is a popular social media with tons of users. One of its most appealing and popular communities is Beauty Blogger, where beauty vloggers create and upload videos about beauty products. This study explored the impact of YouTube beauty vlogger on the attitude of Indonesian women towards locally made cosmetics and their willingness to purchase them. Based on the research results, relevant conclusions and recommendations were proposed which can be used as a reference for future research and practical applications.
\end{abstract}

Keywords: social media, E-word of mouth (E-WoM), beauty blogger

\section{Introduction}

Social Networking Sites were introduced as a consequence of the changes in consumers' communication experiences (Ross et al., 2009). The use of social networking sites allows an individual to find others who share similar interests, whether for romantic or socialization purposes(McKenna et al., 2002). Social media is an emerging media that has developed rapidly in recent years. It is built on Web 2.0 networking technologies and concepts so that people can use them conveniently on their phones, tablets, and computers. With the advancement of digital audio and video technology, a growing number of people are able to film short video clips and share it through social platforms. Moreover, the growing development and popularity of today's Internet technologies facilitate the appearance of social networking sites and web-based audio and video platforms. The development of social media has been witnessed all over the world because almost everyone has access to its services now.

Social media allows users to create different contents to satisfy social behaviors involving communication and interaction with others. It also supports self-creation and content-sharing (Heinonen et al., 2011; Kaplan \& Haenlein, 2010; Rettberg, 2009). The emergence of social networking sites and media sharing sites has created a web-based community that is in constant evolution and development. Furthermore, web applications have become the mainstream for value creation and information exchange (Debei et al., 2013). Since the enhancement of Web 2.0, the source of information has been changed from one-sided provision to two-way communication, allowing individuals and organizations to send and receive messages from each other (Henderson \& Bowley, 2010; Mangold \& Faulds, 2009). Users are able to share information with friends and obtain assistance from community members because of the communication function of social networking sites, such as asking their friends for their opinion regarding products that they want to purchase (Liang et al., 2011). Typically, a social networking site includes a system that can connect members with similar interests; its members and external parties can use the system to create targeted messaging so that messages can be conveyed to possible interested 
members. Users often participate in two activities on social networking sites, which are creating new contents by editing personal files and reading contents created by others (Trusov et al., 2010). Social media platforms, such as Facebook, YouTube, LINE, Instagram, Plurk, Twitter, and Google+, are widely used because of their low cost, and people across all ages and groups can easily use them. Consequently, many enterprises and brands use social media as a marketing tool to communicate with their consumers because of the proliferation, convenience, and immediacy of social media. Various types of social media advertising, in turn, have become popular along with the development of social media marketing. Individuals are also able to express themselves by sharing and creating contents (Strauss \& Frost, 2009).

Social networking sites allow users to create a personal webpage, where they can socialize or interact professionally with friends, connect with other people through common friends, and share information about certain events and gatherings (Cheung \& Lee, 2010; Trusovet al., 2010). Currently, one of the most popular ways of presenting information on social media is through video blogging or vlogging, which makes use of photos and videos to create web contents. Vlogs are often uploaded by vloggers (people who make vlogs) on video platforms such as YouTube. YouTube is a video sharing platform affiliated with Google with a high number of users and is the most downloaded application in the App Store and Google Play. Vlogging is a function that involves filming videos about a variety of topics that can be uploaded to YouTube directly as a webcast or as an edited video. Through YouTube, the uploaded vlogs can be watched by others through the vlogger's channel where users can subscribe, rate videos (like likes or dislikes), and leave comments (Frobenius, 2011).Social media also exert an impact on viewers' search for product information to support their purchasing decisions (Dellarocas, 2003). Content creators can be divided into two categories: amateur users who make videos (user-created content) and creators from traditional media institutions (Burgess \& Green, 2009). A dominant percentage of contents on the Internet are created by vloggers. In recent years, vloggers on YouTube have been multiplying. Unlike TV or radio shows that need large production teams and huge production costs, vloggers, irrespective of type, content, and purpose, are able to create a "virtual environment" controlled by video producers without large production teams and at a low cost, since it is relatively easy and inexpensive for users to post and share information in the form of text, audio, and video on the Internet.

Electronic Word of Mouth (E-WoM) is a phenomenon that occurs when consumers use the Internet to look for feedback and opinions on a particular brand, product, or company (Manzoor, 2010). E-WoM is an informal interpersonal communication between consumers over the Internet about products and services when they are looking for information about a particular brand, product, or company (Hennig-Thurau et al., 2004). Vlogs are an important source of E-WoM for users because they can post reviews and voice their opinions on the platform. Nowadays, consumers can easily obtain diverse information from the Internet and exchange information with each other on the platform to help them make purchasing decisions. Beauty Blogger, one of the most engaging and attractive communities on YouTube, is designed to help consumers provide aesthetic reviews in the form of video and audio. When users watch a vlog, rather than read texts or images, they are more likely to have a clearer understanding of the products because they are able to picture them. Social media create a sense of social presence for users through the availability of an open channel that allows two-way communication (Fortin and Dholakia, 2005). In this way, the audience feels more immersed while watching vlogs. When users interact with others and experience warmth and camaraderie, they relate and interact more deeply (Laffey et al., 2006). On YouTube, numerous beauty videos can be found. These is a great source of information about cosmetics for consumers especially those looking for relevant products or educational and demonstration videos. Many consumers believe that these videos are not commercialized (although some do contain advertising information), and they are objective, and fair. Consequently, the advent of beauty vlogging would help beauty companies market their products because it has considerable influence on its users. Beauty vloggers produce videos to share product information, shopping experience, and daily necessities to attract a number of subscribers, thus becoming socially influential online celebrities. However, there is insufficient research on how these beauty vloggers affect consumers and why they attract specific groups of consumers. Indonesia is the fourth largest country around the world in terms of population. According to Asosiasi Penyelenggara Jasa Internet Indonesia (APJII), Internet users in Indonesia in 2018 were around 1,432,200 (54.68\% of the population); about $87.13 \%$ of them use social media platforms, and $43 \%$ use YouTube (Asosiasi Penyelenggara Jasa Internet Indonesia, 2018). This study aims to explore the influence of YouTube beauty vloggers on the attitudes of Indonesian female consumers towards local brand cosmetics and their purchasing intentions. Both beauty vloggers and beauty consumers were chosen as participants; ten Indonesian female beauty consumers and two famous Indonesian beauty vloggers participated in the qualitative in-depth interview. After the interview, the collected data were analyzed and relevant suggestions were provided, which could serve as a reference for follow-up researchers. 


\section{Literature Review}

\subsection{Social Media Influencers}

The purpose of sharing information is to provide others with additional knowledge. Whether information sharing is spontaneous or requested, the shared information will affect others (Berger, 1992). A new generation of social networking sites has become a mainstream platform for communication and interaction due to the widespread proliferation of the Internet. Its importance in today's society is increasing as well due to the high volume of information users obtain from it (Cheung \& Lee, 2010). Social media influencers (SMI), who represent a new type of independent third-party spokespersons, shape the attitudes of social media users through vlogs/blogs, and tweets (Gorry, 2009). The number of SMIs is growing rapidly. Due to the persuasiveness and influence of SMIs, many companies and brands collaborate with them (Burgess \& Green, 2009). In this respect, their presence should not be underestimated; it is important to understand what makes SMIs "influencers" and how they successfully use E-WoM as a platform to persuade consumers. Thus, SMIs are very helpful to consumers when getting useful product reviews. SMIs do not get their influence from an association with a particular brand. They only have an online persona that others trust and respect. Moreover, many SMIs do not use their influence on promoting and marketing products of a certain brand; most only provide honest and unbiased reviews, helping them gain consumers' trust (Freberg et al., 2011).

Due to the popularity of social networking sites in recent years, marketing professionals have also begun to communicate with customers through social media. Consumers usually use social networking sites mainly for posting, browsing, and sharing contents, replying to messages, and playing videos (Xu et al., 2012). Social networking sites create business value and commercial opportunities that allow Internet users to participate actively. In this way, social networking sites help corporate organizations to attract funds and advertisers (Cheung \& Lee, 2010). Content marketing can be defined as a management process where enterprises identify, analyze, and satisfy customers' demand of gaining profits with the use of digital content distributed through electronic channels (Rowley, 2008). Publishing user-created content has become a popular way of content marketing, which has been the direction that many brand owners are committed to. Through user-generated content, brand owners do not only get various contents but also obtain opportunities to communicate with consumers and gain their trust (O'Hern \& Kahle, 2013; Rowley, 2008). SMIs provide information and opinions about brands, products, and companies on social networking sites. Today's Internet is not only an information transmitter but also a social and interactive medium (Solomon et al., 2016). Furthermore, many consumers put more trust in the contents produced by other consumers when compared to those produced by the company itself. Since consumer trust is vital to the success of content marketing, many companies are dedicated to improving it.

Reviews posted on social media provide relevant information to customers which serve as a reference to help them make informed choices; positive reviews on enterprises are conducive to their word-of-mouth (Ku et al., 2012). The increased popularity of YouTube in recent years led to the emergence of YouTubers, who are individuals that make their own video contents and post them on their YouTube channel. These YouTubers exert their influence on a YouTube community through a variety of unique communication and narrative techniques (Turner, 2010). Many beauty vloggers produce and publish videos related to beauty or cosmetic products on their own personal YouTube account. These individuals are ordinary consumers who make YouTube videos about beauty products and are not affiliated with any brand. Therefore, their beauty vlogs can exert an enormous impact on the purchase intention of other consumers (Pixability Company, 2014). In the beauty community, beauty vloggers, who are important SMIs, have as much knowledge as professionals in the field of beauty and are proactive in seeking relevant information. Also, they provide a different kind of user experience, voice their opinions, and share product information, such as ingredients, pricing, and product purchase channel. The majority of beauty vloggers objectively review various products they have used, providing positive or negative information to consumers. Beauty vloggers provide demonstrations, recommendations, reviews, or a combination of the three on various types of products, such as cosmetics, hair care products, nail products, skin care products, and perfume.

\subsection{Source Credibility}

Many researchers have confirmed that a trustworthy source is more credible than an unreliable one (Wiener \& Mowen, 1986). Source credibility is defined as the attitude toward a source of communication held at a given time by a receiver (Carroll, 2016). Companies or advertising executives take into account a variety of factors in choosing someone to review (or endorse) their products. They take the following factors into consideration when selecting candidates (Shimp \& Andrews, 2010):

- Suitability of endorsers with the target market. 
- Image endorser matching with the brand,

- Endorser credibility,

- Attraction,

- The cost of obtaining the endorser,

- Difficulty or ease of working with the endorser,

- The possibility of a problem arising after all support has been made,

- The number of brands that employ the endorser as their model.

The credibility of appropriate sources increases the market power of brand owners, which is related to the three dimensions of the source credibility model which are: (1) expertise, (2) trustworthiness, and (3) attractiveness (Ohanian, 1990). These are explained in detail below.

\subsubsection{Expertise}

Expertise enables receivers to recognize the source of the influencers (source of information) so that effective and accurate information can be conveyed. Expertise can be sensed through experience, abilities, skills, and knowledge. Celebrity endorsers who are experts in certain fields have higher brand recognition than those who are not seen as experts. The more expertise celebrities have, the more effective they will be as an endorser. Celebrity expertise will not be changed by negative publicity, but trust and credibility will be affected by it (Speck et al., 1988).

\subsubsection{Trustworthiness}

Credibility has been proven to have a significant and direct impact on consumers' behavioral attitudes and intentions. The more credible a celebrity spokesperson is, the better the image of the brand that he/she supports will be. Thus, the credibility of a celebrity spokesperson has to be considered when a brand owner is looking for one. Ifcustomers find that the source is sufficiently credible, they will be willing to follow and accept their opinion and make it their own viewpoint, i.e. internalization (Erdogan, 1999). Trust is very important for customers; the more trust they place on the brand's spokesperson, the more likely they will purchase the brand. However, negative criticisms about the spokesperson will possibly affect consumers' trust in him/her, which in turn will exert a negative impact on the brand image and product sales.

\subsubsection{Attractiveness}

In terms of attractiveness, the physical attractiveness of a spokesperson affects the effectiveness of persuasive communication, which happens through a process called identification. This process occurs when consumers accept an attractive spokesperson simply because consumers want to identify with him/her (Cohen \& Golden, 1972). Attraction results from positive associations; it requires the spokesperson's overall physical appeal, personality, and abilities being shown on social media platforms. It is important to note that source attractiveness may only be useful when a product increases its user attractiveness, as affirmed in the matching model (Erdogan, 1999).

\subsection{Characteristics of Modern E-Commerce Consumers}

With the rise of social networking sites, a growing number of users are spending more time on social platforms. The modern Internet has been seen as a combination of previously developed communication technologies (Bargh \& McKenna, 2004). Specific differences between online media and other traditional media include the degree of control that users have over the environment, the possibility of one-to-one interaction on the Internet, and the possibility of two-way communication (Campbell et al., 2010; Liu \& Shrum, 2002). According to Kotler and Keller (2009), consumers make purchasing decisions through a five-stage process: (1) problem recognition, (2) information seeking, (3) alternative evaluation, (4) purchasing decisions, and (5) post-purchase behavior. Therefore, companies have to exert efforts to create trust, support, and goodwill during consumers' purchase process apart from paying attention and understanding their purchasing behaviors. The main factors affecting consumers' purchasing behavior include cultural, social, personal, and psychological factors (Kotler \& Keller, 2009).

\subsubsection{Cultural Factors}

Cultural, sub-cultural and social classes have a tremendous impact on consumer purchase behaviors. Culture is a major determinant of consumers' desires and behaviors through family and other major institutions. In this aspect, marketers have to understand and pay much attention to the cultural values of each country to better market their products and find opportunities to search for new products. For example, compared with Western 
society, Asian culture values etiquette more. Each culture is made up of sub-cultures that provide more specific information for the identification and socialization of members. Sub-culture includes nationality, religion, ethnic groups and geographic regions. A sub-culture forms an important market segment; companies design products and develop marketing plans based on the specific needs of the consumers in a given market segment. In addition, social members form homogeneous groups that are distinguished by hierarchical orders because of the stratification or differences caused by different amounts of social resources that they have; the homogeneous group members share similar values, interests, and behaviors (Kotler \& Keller, 2009). Online communities, also known as virtual communities, are social groups that emerge after Internet users interact with each other (Rheingold, 1993). They have their own distinctive sub-culture and social class. Many online communities come into being based on the common interests or preferences of the members, for which subculture unique to a certain community gradually forms and becomes its identity. Furthermore, the community members have a sense of belonging and share a sense of trust that members generate through mutual commitment, fostering a sense of community (McMillan \& Chavis, 1986). Therefore, the influence of social media on community members should not to be underestimated in terms of marketing.

\subsubsection{Social Factors}

Social factors refer to roles and social status of reference groups, families, and individuals. Reference groups, which can be divided into primary and secondary groups, are groups that directly or indirectly affect consumers' attitudes or behaviors. A primary group exerts a direct influence on consumers and interacts in a continuous and informal manner, such as family members, friends, neighbors, and colleagues. A secondary group has an indirect impact on consumers, like religious groups, professional associations, and industry associations; more formal interaction and less daily interaction can be observed among its members. Among secondary groups, family has a considerable influence on purchasing behaviors of other family members. Roles and social status refer to a person's role and position in an organization, which also exerts an influence on one's purchasing behavior. When reference groups have a relatively strong influence, marketers should decide how to approach and influence the opinion leaders of the groups. Opinion leaders are often those who provide informal advice or information about a particular product or product category, such as which brand is best, or how to use a product. Opinion leaders are usually highly confident and gregarious, and they often use the product category. To get close to opinion leaders, marketers should identify them through demographic data and psychological characteristics, and identify the media they often use, through which marketers can send messages directly to them (Kotler \& Keller, 2009).

YouTube beauty bloggers, namely Internet celebrities, are important opinion leaders for many people. The rise of social networking sites has made communication and interaction among people more convenient and has expanded interpersonal relationships, allowing users to actively participate in community activities so that they can expand social relationships across social networking sites. In this regard, social networking sites serve as social service platforms that provide a complete set of functions (Carroll, 2016). Social networking sites have a wealth of communication functions, such as text messaging, video sharing, email and blogs, which make websites an ideal platform for individuals to express themselves, know social events, affirm relationships, and expand their personal networks (Carroll, 2016). Due to the inter-connectivity and sociability of social computing technologies, users obtain both technical and social benefits because of the externalities of social networking sites (Zhao \& Lu, 2012); the corresponding applications for social networking sites not only give them technical support for their recreation and interaction on the social platform, but also give them emotional and informational support, i.e. social support (Liang et al., 2011). In social networking sites, a social identity is generated through interactions between users on personal websites or online communities (Cheung \& Lee, 2010). Social media make individuals feel connected to others by allowing them to share experiences and feelings. This also reflects the desire of users to acquire intimacy, meet the needs of social interaction, and feel close or connected to others by means of specific technologies (Zhao \& Lu, 2012).

\subsubsection{Personal Factors}

Consumers' purchase decisions are influenced by personal factors such as age, the phase of their life, employment status, economic status, personality, self-concept, lifestyle, and personal values. The goods and services that a person avails change as his age grows and as he undergoes different stages in life. Also, his career and economic conditions affect his purchase behavior. Personality, self-concept, and psychological characteristics unique to individuals help brands analyze consumers' purchase behavior, including which products and which brands they will likely to buy. Lifestyle refers to an individual's lifestyle and consumption psychology exhibited in their daily life (Kotler \& Keller, 2009). Social networking sites are social platforms that involve personal, social, and technological factors. In other words, the behavior of social media users is not only affected by their personality traits, internal motivations, and external motivations but also influenced by other 
users and social processes in the community (Zhou, 2011). There have been a number of researches on characteristics that individuals display on social media. In this aspect, Ross et al. (2009) explored personality and motivations associated with Facebook use. Hsu and Lin (2008) studied the influence of personal acceptance of technology, knowledge sharing, and social impact on users' attitudes and intentions in the use of social media. $\mathrm{Xu}$ et al. (2012) discussed the factors that influence users in choosing which social networking sites to patronize based on their use and satisfaction. Wolframt and Doll (2001) researched into the motives of adolescents to use the Internet as a function of personality traits, and personal and social factors.

\subsubsection{Psychological Factors}

Psychological factors that affect the choices of consumers mainly include motivation, perception, knowledge (learning), beliefs, and attitudes. Motivation refers to the internal process of initiating, maintaining, and guiding certain behaviors; some motivations are caused by biological factors while others are caused by psychological factors. Perception is the process in which people choose, organize, and translate input information to create meaningful images. It is affected by physical stimuli, environmental stimuli, and the individual's biological conditions. Knowledge is described as the way certain individuals learn from experience. Most learned behaviors are the result of an individual's perceptual process. Through learning and experience, people gain confidence with their choices which affects their attitudes and purchase behavior. Most companies are interested in understanding the beliefs and attitudes that people have on their products and services. Consumer beliefs shape the image of the brand as well as the product itself, and people act on this image. If some of these beliefs about the brand are wrong, this will inhibit consumers to purchase the product. Thus, companies need to launch a campaign to correct them (Kotler \& Keller, 2009).

\subsection{Youtube Beauty Vloggerin Indonesia}

According to the survey conducted by We Are Social(2017), Internet usage in Indonesia has grown very rapidly, far faster than other countries over the world; it has the second largest number of Internet users in the world (about $10 \%$ of the world). In addition, more than $69 \%$ of Indonesians use mobile gadgets to access the Internet, the fourth highest around the world. Based on the global networking index, Internet users in Indonesia are mostly aged between 16 and 64, and mainly use the Internet for social media and messenger. Moreover, the most frequently used social media are YouTube (43\%), followed by Facebook (41\%), and WhatsApp (40\%)(We Are Social, 2017). Women always want to look confident and beautiful. Because of this, many women take good care of their skin and face through the use of cosmetics. In recent years, wearing makeup has become a popular trend, especially for urban people. Most Indonesian women aged between 17 and 35 put on makeup for a variety of purposes on a daily basis or during special occasions. At present, the Indonesian market mainly has two types of makeup products, local makeup products and high-end makeup products. This study focuses on cosmetics made in Indonesia which can be sold in local pharmacies like Watson or in shopping websites. The quality of local makeup products is good for the local climate and the needs of the consumers were taken into account during their development and manufacturing. According to the Indonesian Ministry of Industry, the cosmetics industry grew by $20 \%$ in 2017 , as people realized the importance of cosmetics.

With the popularity of the Internet and the increase in social media platforms, people's habits constantly changed; individuals are no longer interested in reading but are more engrossed in watching videos on social platforms like YouTube. A wealth of interesting and quality contents on YouTube make appearances, and viewers can easily retrieve the movies or channels that they want to watch, so YouTube is becoming increasingly popular. Because of its popularity, YouTube is able to provide its content creators with a source of income. Successful beauty channels create relevant demonstration videos based on what is popular and what is being frequently searched online in a timely manner. The quality of Indonesian local beauty brands has improved immensely mainly due to the influence of beauty vloggers. Consumers who watch and share articles, videos, reviews, and recommendations from these beauty vloggers exert an enormous impact on the content creators. One of Indonesia's most popular beauty vloggers, Rachel Goddard, has more than 1.75 million subscribers on her YouTube channel (as of May 2019); she usually shares a wide range of makeup products and demonstration videos on her channel. Moreover, she analyzes makeup products objectively and professionally and gives advice to users. That is why she has become one of the most popular beauty content creators in Indonesia. She currently works with two Indonesian YouTubers and collaborates with the Indonesian local brand Luxcrimeto create lip gloss. Beauty brands working with well-known beauty vloggers can help them increase their brand awareness and perceived quality, which greatly affects consumers' willingness to buy. Dredge (2016) pointed out that consumers feel more connected and comfortable with YouTubers when they are more engaged with the viewers, share similar humor, and have minimal filters. Customers are allowed to decide on their own whether to subscribe to a certain YouTube channel or not. These correlations prompted this research to analyze the impact of 
beauty vlogger reviews on YouTube on the purchase intention of local makeup brands in Indonesia.

\section{Methodology}

This study aims to explore the impact of YouTube beauty vloggers or beauty influencers on the attitudes of Indonesian female consumers towards Indonesian cosmetics brands and their willingness to purchase locally made beauty products. This study performed personal interviews on beauty vloggers and female beauty consumers. According to Hennink et al. (2011), personal interview as a research method helps scholars gain exact results and allows them to understand more about the case being studied, how interviewees view the case, their images, and their motivation in buying certain products. After the interviews, the qualitative data collected were analyzed and interpreted; qualitative research was used to determine a variety of deep sample perceptions. The research design of this study was patterned after previous relevant researches to explore the impact of social media, if any, on brand perceptions (Creswell, 2009).

\subsection{Interviewees}

In this study, both the beauty vloggers and consumers were personally interviewed but on different instances. The interviews with consumers were conducted anonymously. A total of ten consumers participated and instead of their actual names, they were labeled A through J. The consumers were aged between 17 and 29, who use social media and wear makeup on a daily basis. All survey respondents were women who lived in Indonesia or in Taiwan who were interested in Indonesian beauty YouTube vloggers. Consequently, two Indonesian YouTube beauty vloggers who had reviewed many local products in their YouTube channel were recruited as participants to better understand the perspective of beauty creators. The two beauty vloggers had been engaged in the makeup field for a long time and had given much content about local cosmetics products. Diah Paramitha is one of Indonesia's beauty bloggers who is active in blogs and social media such as YouTube and Instagram. She is an undergraduate and lives in Bali. She had provided a great deal of information and reviews about local and international makeup and skincare products. The other beauty vlogger interviewed was TjutImani Yuzar. She works in Female Daily Company, and publishes content in the Female Daily YouTube Channel under the "Tried and Tested" program. The basic demographic data of interviewees are summarized in Appendix 1.

\subsection{Content of Interviews}

A semi-structured interview was performed in this study. A total of six main topics were included to allow the researcher to delve into the topic from different perspectives. Relevant literature was also accessed to understand survey respondents' answer to support the research topic. The advantage of a semi-structured interview is that interviewers and interviewees can explore a topic together through meaningful conversations. The first part of the interview involved questions about the participants' personal information. The interviewees were asked to provide their background information and basic knowledge of the YouTuber that they follow. This step was aimed to familiarize the participants with the topic to prepare them for further questions. The second part of the interview involved the interviewees' perception of YouTubers (how do you feel about YouTubers?). This question was designed to understand why participants are willing to spend their time on YouTube and why they trust these YouTubers. The third topic involved the participants' impressions on Indonesian makeup products wherein the participants' knowledge in local makeup brands were assessed. The fourth topic was closely related to the previous question. The participants were asked to talk about the external factors that influence their purchase; it was hoped that a theory regarding consumers' intentions of purchasing Indonesian cosmetics would be derived. The last step involved asking the participants how they want beauty influencers in YouTube to introduce a product, which is concerned about the marketing style, and what product they wish YouTube influencers to introduce. This provided knowledge about how the subscriber would like to be influenced. The collected data are also valuable for beauty influencers.

\subsection{Time and Place of Interview}

This study adopted a semi-structured interview (SSI), to help guarantee that the conversation would revolve around the topic and would follow the established agenda, rather than performing a standard survey interview. This may also result in the discovery of possible unexpected problems. A SSI takes longer than telephone surveys, although it is rarely adopted in focus groups. An hour is considered a reasonable maximum length for SSI to minimize fatigue for interviewers and respondents. This study conducted the interviews between January 2019 and March 2019 to gather data in Indonesia and Taiwan. The interview was conducted in two ways: face-to-face interview with Indonesian participants residing in Taiwan, and online interview using the video call function of WhatsApp for participants residing in Indonesia. All interviews were recorded to ensure the safekeeping of data and to provide more freedom and comfort for the interviewer. The interview recordings were later transcribed for data analysis. The interview lasted for 20 to 30 minutes per participant. During the interview, 
participants were first asked about their age, occupation, and their favorite influencer before specific questions about local cosmetics products and the influence of beauty vloggers. For beauty influencers, a deeper discussion was facilitated to encourage them to talk about how they make their own content. The interview outlines are shown in Appendices 2 and 3.

\section{Analysis and Result}

After qualitative interviews came to an end, the answers of the interviewees were collated as follows.

\subsection{Consumers' Cognition of YouTubers}

There were four questions included in the interview about consumers' perception on YouTube influencers. Interviewee E said that sometimes YouTubers focused more on promoting the products that they are endorsing rather than giving an honest product review. She said that the reviews for sponsored products sometimes appear fake and dishonest; in spite of this, she still follows and watches reviews from YouTube. According to her, she only follows YouTubers who she thinks are trustworthy. Meanwhile, participant A had many thoughts in this aspect; since she started selling makeup products, she has become inclined to believe that makeup reviews on YouTube are really reliable. She followed makeup trends on YouTube, and got to know how to sell their products using YouTubers' product review. Moreover, participant B said that since she does not have enough time to read every article on blogs, she depends on YouTube videos because she could easily see the effect of the product based on the review. Consequently, participant D said that since she is interested in learning how to apply makeup, she feels that YouTube videos have really helped her improve her makeup application. Also, participant $\mathrm{D}$ mentioned that she always learn new tips and techniques every time she watch a beauty vlogs on YouTube; thus, she finds YouTube vlogs reliable. As for their thoughts on YouTube, some participants agreed that there was marketing in some video contents. Participant $G$ said that she notices some advertising information in beauty reviews; however, this has never been a problem for her. According to participant I, she is well aware that some of the beauty videos that she had watched contained endorsements especially those of product reviews. She also mentioned that there was one YouTuber who she thinks is unreliable because all of the products the influencer reviewed were sponsored and the reviews seemed dishonest. She felt that those products were not worth buying because they were not genuinely reviewed.

On the other hand, Interviewee A thinks that some YouTubers provided genuine product reviews because reliable Beauty Vloggers always choose trustworthy brands and shops before sharing their reviews. In addition, Participant $C$ said that when more than one influencer had given good reviews on a specific product, it made her feel that the product is good and is worth buying. Participant E said that she would be inclined to think that the review is genuine if the beauty vlogger has been using the product daily for a long time rather than just once. For her, a product reviewed only once would mean that the product was sponsored. Thus, she would not buy this type of product. Further, Participant $\mathrm{H}$ mentioned that she would compare the videos and reviews provided by different beauty vloggers about a single product to ensure its authenticity. Participant F said that in addition to watching videos and reading relevant reviews, she would also search for other product information for confirmation.

\subsection{Opinions on Local Makeup Products}

Currently, Indonesian local makeup products are increasing rapidly. Since Indonesians are composed of different races and skin colors, sometimes it is difficult for them to buy a foreign product that would suit their needs. Indonesians have five types of skin tone and color, white porcelain, ivory white, brown, dark, and yellow complexion. Western products may be too light or too dark for some Indonesians' skin color; similarly, Korean products may be too light. It is possible that all of the interviewees have tried Indonesian cosmetics because they are more suitable for their skin type and color. Consequently, this part of the interview focused on their knowledge about Indonesian cosmetics, their experience of using them, and how they found local cosmetics. Many female interviewees mentioned one important factor as to why they choose Indonesian-made products: because local makeup products are halal-certified makeup products. Most of Indonesian-made cosmetics are halal-certified; thus, it is more convenient for Indonesians to buy these products rather than look for an international product that is halal-certified. Further, neither Korean nor western makeup products are halal-certified; therefore, buying foreign products requires them to read the ingredients. As compared to Indonesian brands, they just need to look for the halal-certified label. A majority of Indonesians are Muslims, so it is more common for them to use halal products than non-halal products. Some non-Muslims also like to use halal products because the ingredients include fewer chemicals, which is believed to be better for the skin.

Interviewee A has used local makeup products for a while and feels that their quality has become better than before. In particular, the popularity of e-commerce enabled local makeup products to increase rapidly because it 
has become easy for people to find relevant product information and make a purchase. Participant $\mathrm{C}$ mentioned that she used local products mainly because they were less expensive. In addition, it was easy for her to buy the products she wanted at a pharmacy or supermarket near her home. In addition, participant $\mathrm{D}$, who is very interested in makeup, mentioned that she chooses a brand based on what she needs or what fits her skin, so place of origin of the makeup product is not a major factor for her. However, she also considers the differences between local brands and international brands because she had watched many reviews on YouTube about local makeup brands. Interviewee $\mathrm{E}$ mentioned that it was easier for her to buy and use local makeup products. Participant $\mathrm{G}$ mentioned that it has become easier for her to find quality makeup products, especially local makeup products since YouTube, Instagram, blogs and other social media emerged and became popular.

\subsection{YouTubers' Influence on Viewers' Purchase Behavior}

Basically speaking, if someone wants to earn money on YouTube, one needs to upload videos that are original and do not violate the copyright regulations imposed on it. In this way, one may get the opportunity to be included in advertising programs on YouTube. This process is called monetization. The monetization of YouTube videos means that YouTube or Google is allowed to load advertisements on videos that have been uploaded and in return, YouTubers get a share of the advertising avenue ( $45 \%$ for YouTube and $55 \%$ for the content creator). The video monetization is realized under the circumstance that a YouTube channel have joined the YouTube Partner Program and the uploaded videos meet the minimum requirements to be monetized which are as follows:

- Content must be friendly to advertisers,

- The person who made the content has obtained the permission to use it commercially,

- The person must provide documentation that proves ownership of commercial rights to all audio and video contents,

- Content must comply with YouTube Partner Program policies, YouTube Service Requirements, and Community Guidelines. YouTube has the right to deactivate monetization on accounts that do not comply with the guidelines.

On condition that content creators of YouTube comply with the aforementioned criteria, they will have the opportunity to earn money by creating contents on the platform. The more people watch the videos and advertisements displayed, the greater the chance for content creators to earn money will be. This provides YouTubers with incentives to create captivating contents to get publications and engagement. It is also beneficial for companies because when YouTubers advertise their products through their own videos, it is expected that YouTube viewers or subscribers will pay more attention to the product, which may make them feel inclined to buy it. This section of the interview revolved around whether YouTubers market products by providing advertising information on videos and whether the commercialized videos have an impact on the buying behavior of YouTube viewers (Source: https://support.google.com/youtube).

Many interviewees said that they had purchased the products that beauty vloggers recommended on their videos or product reviews. Interviewee $\mathrm{H}$ shared her own experience: she bought a skin care product (toner) because of the review made by a beauty vlogger on YouTube, but she felt that the skin care product did not have a good effect on her skin after using it. She thought the unsatisfactory effect may be caused by the difference in skin types. After that experience, she has become more cautious about the comments on video blogs regarding beauty products and would not be easily affected. Participant $G$ said that after watching beauty vloggers' videos and reading their product reviews, she would be more inclined to immediately search online for product information so that she could purchase the product online. Also, she rarely went to physical stores to purchase. Further, Participant $\mathrm{J}$ said that although she would be affected by the videos or product reviews of beauty vloggers, she would always ask the opinion of a friend who has purchased and used the product before buying it for herself. Participant C said that beauty vloggers' videos and product reviews have limited impact on her because most beauty vloggers are good-looking, so the products may be right for them, but not necessarily for other consumers. Moreover, Participant A said that she learned about the latest trend of beauty products through social media platforms. She believes that YouTube has a great influence on consumers' decisions in buying beauty products, especially for the followers of Beauty Influencers. Participant F believes that YouTube did not help her find the right beauty products for her, and the information she needed may not necessarily come from the videos or product reviews of beauty vloggers. Lastly, Participant F said that the information she needs may come from manufacturers or other consumers.

\subsection{External Factors for Purchase Decision}

Buyers' decision-making process includes several steps such as introduction of needs, information seeking and 
evaluation of alternatives, buying, and post-purchase behavior. This section explains how a customer makes a decision, the factors that influence their purchasing decisions, the basics of purchase intentions, the influence of external factors and status on their buying behavior, and the influence of the surrounding environment that leads to their purchase behavior. Most interviewees said that in addition to considering their skin type and budget when purchasing beauty products, they also ask other people (such as family members, friends, colleagues, classmates) for advice and recommendations based on their experience. Obtaining information through videos and product reviews is convenient and effective for them. Some interviewees also indicated other important considerations including product quality, ingredients, family values, and halal certification.

\subsection{Suggestions for YouTubers}

Many interviewees pointed out that they expect beauty vloggers to maintain a genuine attitude when they comment on products. They hope that content creators remain sincere and do not exaggerate the efficacy of the product or even deceive viewers because of sponsorship. They all hope that beauty vloggers review the products more specifically and explain it in an honest manner. Most interviewees believe that YouTube is the most influential marketing platform, and videos that have audio visual effects allow viewers to distinguish the products in an entertaining manner. In addition, many interviewees said that photos, videos, and posts on Instagram and Facebook affect their purchase behavior. In this regard, it is suggested that beauty vloggers should combine YouTube with other social media, such as Instagram and Facebook, to achieve better results.

\subsection{YouTubers' Perception on Whether Their Contents Encourage Others to Make a Purchase}

Two Indonesian makeup influencers participated in the interview, I Gusti A. PutuDiahParamitha and TjutImaniYuzar. I Gusti A. PutuDiahParamithais active in blogging, and in posting on Instagram and YouTube. She was 20 years old at the time of the interview, and her passion for makeup pushed her to make her first product review. Aside from being an active content creator, she is also studying in Bali State Polytechnic. She started sharing makeup product reviews when she decided to become a content creator. She was inspired by Jen from Head to Toe (Korean YouTuber) and Alodia (Indonesian blogger) who are passionate social media influencers. Their passion made her want to challenge herself. She is keen on reviewing local skin care products and local cosmetics because she wants people to know and feel proud of Indonesian local makeup products. She provided information on how to use those products in her reviews. Although she endorsed some beauty products, she chose to provide honest product reviews instead of lying because she wanted to bring the right products to people who need them. She also shared her opinions on other local beauty products, believing that currently, Indonesian brands of skin care products and cosmetics were marketed based on the needs of customers and the attractiveness of the millennial era, and the local brands have become more diverse and have grown more rapidly. She said she sticks to her own criteria when choosing a content to be uploaded, emphasizing that she only uploads reviews of the products made from premium ingredients, especially natural ingredients, and licensed by the Health Department/BPOM (Indonesian National Agency of Drug and Food Control). To market products on her channel, she usually put pictures on Instagram and provided links of her full review on her YouTube/blog so that people who are interested in the product would swipe up and watch the video. She hopes that her shared contents would be received positively so that more people will know and use local quality skin care and makeup products in Indonesia.

The other content creator who participated in this study is TjutImaniYuzar. She is a video content editor in Female Daily Network, an Indonesian company that focuses on makeup and skin care products. The company has its own YouTube channel. She has her own segment on YouTube called FD Tried \& Tested, where she tries and give reviews to new and unique products. According to her, they managed to maintain her and her company's integrity on their beauty platform, so they do not have specific strategies to promote their products. They also do not recommend their platform because they believe that their content should speak for itself and those who read their content would follow them on Instagram and become their member because they believe in the credibility of Female Daily. She also shared how she chooses products to be put on her video. Usually, local brands send their products to their company; then they choose products that have already been certified by the BPOM. The selected products are sent to the editorial team who will scrutinize and examine the products and their ingredients and assess if they meet all internal standards. Lastly, they make content with the qualified products. Female Daily has established Female Daily Award to show appreciation to the brands. Female Daily Best of Beauty Award is an annual event meant to showcase the best brands; the award winner is completely chosen by Female Daily members. In 2018, more than 16,000 people participated in voting their favorite product. Their goal is to make Female Daily a media platform that will bring companies and members to participate in a bazaar; it has established the biggest beauty bazaar in Indonesia with a total of 19, 000 visitors in 2018. These two content creators gave their opinions on how both managed to create contents with honest product reviews, 
and how they chose the products they would review. They believe that their viewers appreciate the contents they make. Further, they think that the information they provide may motivate viewers to make a purchase decision so they do not want their subscribers to lose faith in their content. Their goal is to help people experience more and bridge the gap between brand companies and buyers.

\section{Conclusions}

The research results show that the majority of interviewees are affected by YouTubers' videos and reviews. Interviewees take a keen interest in their reviews when YouTubers provide information in an honest manner rather than because of commercial sponsorship. Interviewees understand that content creators need sponsors to earn their income. On the other hand, credibility will be relatively low if there is too much commercial content in their product reviews. In addition, most interviewees not only followed influencers on their YouTube channels where they watch videos and read product reviews, but also on their other social media accounts like Instagram and Facebook. In particular, Instagram has recently been popular with young women because they allow users to post images and videos. Oftentimes, product-related information can be found on the influencers' Instagram or Facebook account aside from their YouTube channel. YouTuber influencers play an important role in connecting brands through product reviews and YouTube viewers. They thought to be more convincing to their followers than traditional brand messages. Therefore, marketers and communication specialists must develop brand-consumer dialogues on digital platforms via YouTubers. It can be said that YouTubers know exactly their target customers and as a brand ambassador, they can help brands approach YouTube viewers with ease.

The research revealed that social media, especially YouTube, are the most effective platform because people are more interested in watching contents on social media rather than on television. In this era, people find social media helpful because they can get information more quickly. On the other hand, respondents have pointed out that they cannot completely believe in YouTubers' reviews because they know that some reviews are marketing styles despite being viewed as attractive and natural. Trust plays a big role in this part. Even though some respondents do not trust YouTubers entirely, mainly due to commercialized content, they still trust their own opinions when it comes to products or services. Further, participants agreed that they still consider influencers' opinions prior to purchasing a product. They trust YouTubers' words and believe that they are reliable, hence purchase products even though YouTubers do marketing and provide commercialized content. The extent on which YouTube play an important part in consumers' buying decision depends on the consumers' trust on the content creators and the degree to which they relate to them. YouTube content creators are viewed as more genuine and friendly compared to celebrities in television. Usually, YouTubers create Instagram posts to interact with their subscribers. This part is essential to content creators because they will examine the age, gender, and occupation of their subscribers and potential consumers. If viewers are able to relate to YouTubers, they will subscribe to their channel, thereby gaining their trust. In this case, YouTubers having earned the credibility of viewers will result in increased recognition of other viewers. In this aspect, effective marketing is useful for YouTubers and companies. In addition, interviewees like to compare videos and reviews of a product because comparisons help them make better choices. If they do not have any product experience, they tend to change their intuition about YouTubers' behaviors and opinions, which means that they are positively influenced by the YouTubers and even trust their purchasing decisions.

In terms of local makeup products, local brands use social media to introduce their products. Also, they work with content creators to improve product awareness and preferences through YouTubers. Viewers' decision making allows marketers and content developers to support viewers throughout the process. This is done to accompany public opinions that viewers are aware of at the beginning of their purchase decision-making process and guide them through the process using customers who have experienced the products by sharing positive word of mouth. By knowing the decision-making process of viewers, YouTubers are able to find the "right" viewers for their contents and the correct tools to influence them, making them think that the product being reviewed is what they need after watching the influencers' videos. In this regard, YouTubers' channel provides promotional content because it promotes sales. All respondents have sought needs, searched for more information, and have made purchases. The posted content, which is important to purchase, determines the credibility of a YouTuber. It will have a positive effect on YouTubers if they are able to make customers feel satisfied and when the customer recommends them to others. Conversely, it will have a negative impact if the product that YouTubers recommend does not match the expectations of the viewers; YouTube viewers' trust in YouTubers will be impaired and their credibility will be questioned. This process is of great importance for crucial choices. YouTube viewers' purchase behavior and their decision-making process are also influenced by external factors that guide their behavior, such as value, convenience to buy, comfort, trademark, YouTuber review, and recommendation from friends. Furthermore, interesting findings are made because YouTubers who 
recommend products are called external influencers. This proves that it is possible to use similar commercial content for different viewers. Some respondents said that if there are good value-based online stores that provide services in the Indonesian language, which would make it easier for Indonesians to shop, they will choose to shop online. YouTubers take part in this because they may influence their audience's decision to purchase online or not based on the YouTubers' experience. Another important point is the YouTuber 'sales speech' and the way products are presented. Contents must be interesting, entertaining, and informative but not too wordy. If viewers have given their time and confidence to YouTubers, it means that they are able to exert a positive influence in consumers' purchase decision.

The growth of social media, especially YouTube, has helped people witness a new phenomenon in Indonesia. Through marketing and influence, companies have collaborated with YouTubers to improve their sales. The majority of interviewees think that the key to the influencing viewers is trust. If viewers trust the YouTuber, they could contribute positively to all aspects of their buying behavior. The participants explained that they trust YouTube influencers more than their TV counterparts because the YouTubers are first and foremost customers just like them; therefore, they value their experience and opinions on the products they intend to purchase.

As content creators, YouTube influences understand that they have the capacity to change viewers' perception and their purchasing decisions. Therefore, they need to set certain standards when choosing which brand they will collaborate with because it will affect viewers' trust. Through YouTube and its influencers, local products could stand out in the Indonesian market. There are many examples of successful collaborations between a local brand and a YouTuber, such as Tasya Farasya and mineral botanica henna night lips, and canggu highlighter by Rachell Goddard and Mizzu Cosmetic.

\section{Limitations and Suggestions for Future Research}

This research helps to understand the impact of YouTubers as "brand ambassadors" on viewers' decision to purchase Indonesian cosmetics. Also, the external factors that influence their purchase were analyzed. Moreover, this study did not consider how companies choose an influencer to become their online brand ambassador. There are similar researches in developed countries, such as the US or some European countries, but there is few specific research on the impact of social media on local products, especially in a developing country like Indonesia. Consequently, research results were totally different partially because local makeup products in developed countries are already very well known by other nations in South East Asia while Indonesian products are relatively new to locals. Secondly, there are only a small number of people who participated in this research; only ten consumers and two influencers. In this regard, the sample size may be insufficient to guarantee reliable research results. On the other hand, the small number of participants in this research made it possible to conduct in-depth interviews. Thus, it allowed interviewees to give detailed and in-depth information, which laid a good foundation for later research. Furthermore, the interviewees had a deep understanding of the topic and considerable experience. Another limitation in this study is the language barrier. The interview questions were stated in English, but some interviewees are unable to speak English well; therefore, some questions had to be translated in Indonesian. There is a possibility that some information may have been distorted in translation and some information that were difficult to express in English were lost. Also, some respondents had difficulties expressing themselves in English and may not have been able to say everything that they had wanted to say. Therefore, it would be helpful if both the interviewer and the respondents could speak English and the native language so they will be able to understand each other and converse well.

Since the Indonesian cosmetics industry is relatively new in the market, there are opportunities to do more research on the growth of YouTubers as marketing tools to promote Indonesian products and their impact on the purchase decision of viewers. Kotler and Armstrong (2008), who are seen as "marketing gurus", proposed that consumer buying behaviors have existed for a long time, but the knowledge on it do not change very much; thus, there is still time for researchers to understand more about this phenomenon. Indonesian local cosmetics brands need to take advantage of the social media phenomenon since this is an opportunity for them to achieve breakthroughs and improve customers' perceptions on their products. Local brands could collaborate with YouTubers to further help them grow. Also, this study suggests that YouTubers must strive to give product reviews in an honest manner, since they exert a great impact on their viewers' purchase decision. It is hard for YouTubers not to accept sponsorship, but they need to choose the brands that they will accept wisely.

Another limitation of this research is the exclusion of respondents aged between 15 and 21. This age group was believed to be relatively starting in their use of makeup. In this aspect, the research result could not be applied to this age group. On the other hand, this research conducted an in-depth interview about the relevant experience of consumers who have been using make up on a daily basis. Based on this research, beauty vloggers exerted an 
influence on the purchase intention of customers; therefore, companies are recommended to collaborate with beauty vloggers especially those who can easily relate with the general public in order to increase the chance of buyers purchasing their product. Consumers are advised to take into consideration the quality of makeup products before making a purchase. Consumers are also recommended to pay attention to the brands that beauty vloggers are endorsing because it can help consumers examine the credibility of the cosmetic product, especially local makeup products that are still in the process of developing their quality and market expansion. Lastly, for future researchers, it is hoped that this research will be useful as a reference when they conduct further research on beauty vloggers and the purchase intention of consumers. In addition, it is suggested that further research examine other variables such as purchasing decisions and brand image. Moreover, further research can use different research methods to allow comparison of results and better generalizability.

\section{References}

Asosiasi Penyelenggara Jasa Internet Indonesia (APJII). (2018). Retrieved from https://www.teknopleanur.com

Bargh, J. A., \& McKenna, K.Y. A. (2004). The Internet and social life. Annual Review of Psychology, 55, 573-590. https://doi.org/10.1146/annurev.psych.55.090902.141922

Berger, H., \& Luckmann, T. (1992). The social construction of reality. NY: Penguin.

Booth, N., \& Matic, J. (2011). Mapping and leveraging influencers in social media to shape corporate brand perceptions. Corporate Communications, 16(3), 184-191. https://doi.org/10.1108/13563281111156853

Burgess, J., \& Green, J. (2009). YouTube: Online video and participatory culture. UK: Polity Press.

Campbell, D. E., Wright, R. T., \& Clay, P. F. (2010). Deconstructing and operationalizing interactivity: An online advertising perspective. Journal of Information Technology Theory and Application, 11(4), 29-53. https://doi.org/10.1108/13563281111156853

Carroll, C. E. (2016). Encyclopedia of corporate reputation. CA: Thousand Oaks, Sage Publications.

Chen, R. (2013). Living a private life in public social networks: An exploration of member self-disclosure. Decision Support Systems, 55(3), 661-668. https://doi.org/10.1016/j.dss.2012.12.003

Cheung, C. M. K., \& Lee, M. K. O. (2010).A theoretical model of intentional social action in online social networks. Decision Support Systems, 49(1), 24-30. https://doi.org/10.1016/j.dss.2009.12.006

Cohen, J. B., \& Golden, E. (1972). Informational social influence and product evaluation. Journal of Applied Psychology, 56(1), 54-59. https://doi.org/10.1037/h0032139

Creswell, J. W. (2009).Research design: Qualitative, quantitative, and mixed methods approaches (3rd ed.). CA: Thousand Oaks, Sage Publications.

Debei, M. M. A., Lozi, E. A., \&Papazafeiropoulou, A. (2013). Why people keep coming back to Facebook: Explaining and predicting continuance participation from an extended theory of planned behaviour perspective. Decision Support Systems, 55(1), 43-54. https://doi.org/10.1016/j.dss.2012.12.032

Dellarocas, C. (2003). The digitization of word of mouth: Promise and challenges of online feedback mechanisms. Management Science, 49(10), 1407-1424. https://doi.org/10.1287/mnsc.49.10.1407.17308

Dredge, S. (2016). Why are YouTube stars so popular? The Guardian. Retrieved from https://www.theguardian.com/technology/2016/feb/03/why-youtube-stars-popular-zoella

Erdogan, Z. (1999). Celebrity endorsement: A literature review. Journal of Marketing Management, 15(4), 291-314. https://doi.org/10.1362/026725799784870379

Fortin, D. R., \& Dholakia, R. R. (2005). Interactivity and vividness effects on social presence and involvement with a Web-based advertisement. Journal of Business Research, 58(3), 387-396. https://doi.org/10.1016/S0148-2963(03)00106-1

Freberg, K., Graham, K., McGaughey, K., \& Freberg, L. (2011). Who are the social media influencers? A study of public perceptions of personality.Public Relations Review, 37(1), 90-92. https://doi.org/10.1016/j.pubrev.2010.11.001

Frobenius, M. (2011). Beginning a monologue:The opening sequence of video blogs.Journal of Pragmatics, 43(3), 814-827. https://doi.org/10.1016/j.pragma.2010.09.018

Gorry, G. A. (2009). Winning the Internet confidence game. Corporate Reputation Review, 12(3), 195-203. https://doi.org/10.1057/crr.2009.16 
Heinonen, K. (2011). Consumer activity in social media: Managerial approaches to consumers' social media behavior. Journal of Consumer Behaviour, 10(6), 356-364. https://doi.org/10.1002/cb.376

Henderson, A., Bowley, R. (2010). Authentic dialogue? The Role of "friendship" in a social media recruitment campaign. Journal of Communication Management, 14(3), 237-257. https://doi.org/10.1108/13632541011064517

Hennig-Thurau, T., Gwinner, K. P., Walsh, G., \& Gremler, D. D. (2004). Electronic word-of-mouth via consumer-opinion platforms: What motivates consumers to articulate themselves on the Internet? Journal of Interactive Marketing, 18(1), 38-52. https://doi.org/10.1002/dir.10073

Hennink, M., Hutter, I., \& Bailey, A. (2011). Qualitative research methods. London: Sage Publications.

Hsu, C. L., \& Lin, C. C. (2008). Acceptance of blog usage: The role of technology acceptance, social influence and knowledge sharing motivation. Information \& Management, 45(1), 65-74. https://doi.org/10.1016/j.im.2007.11.001

Kaplan, A. M., \& Haenlein, M. (2010).Users of the world, unite! The challenges and opportunities of social media. Business Horizons, 53(1), 59-68. https://doi.org/10.1016/j.bushor.2009.09.003

Kotler, P., \& Armstrong, G. (2008). Principles of marketing (12th ed.). NJ: Pearson Prentice Hall.

Kotler, P., \& Keller, K. (2009). Marketing management (13th ed.). United Stated: Pearson.

Ku, Y. C., Wei, C. H., \& Hsiao, H. W. (2012). To whom should I listen? Finding reputable reviewers in $\begin{array}{lllll}\text { opinion-sharing communities. Decision Support Systems, } & \text { 53(3), }\end{array}$ https://doi.org/10.1016/j.dss.2012.03.003

Laffey, J., Lin, G. Y., \& Lin, Y. (2006). Assessing social ability in online learning environment. Journal of Interactive Learning Research, 17(2). 163-177. https://www.learntechlib.org/primary/p/5981/

Liang, T. P., Ho, Y. T., Li, Y. W., \& Turban, E. (2011). What drives social commerce: The role of social support and relationship quality. International Journal of Electronics and Communications, 16(2), 69-90. https://doi.org/10.2753/JEC1086-4415160204

Liu, Y., \& Shrum, L. J. (2002). What is interactivity and is it always such a good thing? Implications of definition, person, and situation for the influence of interactivity on advertising effectiveness. Journal of Advertising, 31(4), 53-64. https://doi.org/10.1080/00913367.2002.10673685

Mangold, W. G., \& Faulds, D. J. (2009). Social media: The new hybrid element of the promotion mix. Business Horizons, 52(4), 357-365. https://doi.org/10.1016/j.bushor.2009.03.002

Manzoor, D. A. (2010). E-Commerce: An introduction. Deutschland: Lap Lambert Academic Publishing.

McKenna, K. Y. A., Green, A. S., \& Gleason, M. E. J. (2002). Relationship formation on the Internet: What's the big attraction? Journal of Social Issues, 58(1), 9-31. http://dx.doi.org/10.1111/1540-4560.00246

McMillan, D. W., \& Chavis, D. M. (1986). Sense of community: A definition and theory. Journal of Community Psychology, 14(1), 6-23. https://doi.org/10.1002/1520-6629(198601)14:1<6::AID-JCOP2290140103>3.0.CO;2-I

O'Hern, M. S., \& Kahle, L. R. (2019). The empowered customer: User-generated content and the future of marketing. Global Economics and Management Review, 18(1), 22-30. https://doi.org/10.1016/S2340-1540(13)70004-5

Ohanian, R. (1990).Construction and validation of a scale to measure celebrity. Journal of Advertising, 19(3), 39-52. https://doi.org/10.1080/00913367.1990.10673191

Pixability Company. (2014). Beauty on YouTube: How YouTube is radically transforming the beauty industry and what that means for brand. Retrieved from https://www.pixability.com

Rettberg, J. W. (2009). Freshly generated for you, and Barack Obama: How social media represent your life. European Journal of Communication, 24(4), 451-466. https://doi.org/10.1177/0267323109345715

Rheingold, H. (1993). The virtual community: Homesteading on the electronic frontier. Massachusetts: Addison-Wesley.

Ross, C., Orr, E. S., Sisic, M., Arseneault, J. M., Simmering, M. G., \& Orr, R. R. (2009). Personality and motivations associated with Facebook use. Computers in Human Behavior, 25(2), 578-586. https://doi.org/10.1016/j.chb.2008.12.024 
Rowley, J. (2008). Understanding digital content marketing. Journal of Marketing Management, 24(5/6), 517-540. https://doi.org/10.1362/026725708X325977

Shimp, T., \& Andrews, J. (2010). Advertising promotion and other aspects of integrated marketing communications (8th ed.).Canada: South-Western College Pub.

Solomon, M., Bamossy, G., Askegaard, S., \& Hogg K. (2016). Consumer behaviour: A European perspective (6th ed.). England: Prentice Hall.

Speck, P., Schumann, D., \& Thompson, C. (1988). Share celebrity endorsements-scripts, schema and roles: Theoretical framework and preliminary tests. Advances in Consumer Research, 15, 68-76. http://acrwebsite.org/volumes/6799/volumes/v15/NA-15

Strauss, J., \& Frost, R. (2009). E-Marketing (5th ed.). NJ: Upper Saddle River, Pearson Prentice Hall.

Trusov, M., Bodapati, A. V., \& Bucklin, R. E. (2010). Determining influential users in internet social networks. Journal of Marketing Research, 47(4), 643-658. https://doi.org/10.1509/jmkr.47.4.643

Turner, G. (2010). Ordinary people and the media: The demotic turn. UK: Sage.

We Are Social. (2017). Retrieved from https://wearesocial.com/special-reports/digital-in-2017-global-overview

Wiener, J. L., \& Mowen J. C. (1986). Source credibility: On the independent effects of trust and expertise. Advances in Consumer Research, 13, 306-310. http://acrwebsite.org/volumes/6509/volumes/v13/NA-13

Wolfradt, U., \& Doll, J. (2001). Motives of adolescents to use the Internet as a function of personality traits, personal and social factors. Journal of Educational Computing Research, 24(1), 13-27. https://doi.org/10.2190/ANPM-LN97-AUT2-D2EJ

Xu, C., Ryan S., Prybutok, V., \& Wen, C. (2012). It is not for fun: An examination of social network site usage. Information \& Management, 49(5), 210-217. https://doi.org/10.1016/j.im.2012.05.001

Zhao, L., \& Lu, Y. (2012). Enhancing perceived interactivity through network externalities: An empirical study on micro-blogging service satisfaction and continuance intention. Decision Support Systems, 53(4), 825-834. https://doi.org/10.1016/j.dss.2012.05.019

Zhou, T. (2011). Understanding online community user participation: A social influence perspective. Internet Research, 21(1), 67-81. https://doi.org/10.1108/10662241111104884

Appendix 1. Basic demographic data for interviewees

\begin{tabular}{|c|c|}
\hline Code & ata summary \\
\hline A & $\begin{array}{l}\text { A } 23 \text {-year-old student, who owns an online shop, and follows TasyaFarasya, Rachell Goddard, and Ayi on } \\
\text { YouTube and Instagram. She regularly watches their YouTube videos and keeps track of their activities, which } \\
\text { they update daily on Instagram. She is interested in their content because she sells makeup products and needs to } \\
\text { be updated on the available cosmetic products in the market in a timely manner. }\end{array}$ \\
\hline B & $\begin{array}{l}\text { A } 24 \text {-year-old student who works occasionally. She follows Rachell Goddard, SuhaySalim, and Female Daily on } \\
\text { YouTube and Instagram. Respondent B watches their YouTube once a week. She sometimes reads their } \\
\text { Instagram update because she does not have much free time. }\end{array}$ \\
\hline $\mathrm{C}$ & $\begin{array}{l}\text { A } 22 \text {-year-old full-time student who watches videos uploaded by Gita Savitri on YouTube who often uploads } \\
\text { videos about traveling, and does makeup tutorial so she watches everything that this YouTuber posts. }\end{array}$ \\
\hline D & $\begin{array}{l}\text { A } 22 \text {-year-old who follows TasyaFarasya, Rachell Goddard, and SuhaySalim on YouTube (more often) and } \\
\text { Instagram. She watches their videos and tutorials daily because she is interested in makeup and wants to know } \\
\text { new trends. }\end{array}$ \\
\hline E & $\begin{array}{l}\text { A } 22 \text {-year-old student who prefers journal reviews to video reviews. Sometimes, she watches makeup videos } \\
\text { from Nanda Arsyinta or some product reviews when she needs some recommendations on products to use in her } \\
\text { daily life. }\end{array}$ \\
\hline $\mathrm{F}$ & $\begin{array}{l}\text { A } 22 \text {-year-old student who watches videos from TasyaFarasya, Nanda Arsynta, and Sunnydahye. She watches } \\
\text { videos from YouTube almost every day. Not only does she watch makeup tutorials, but also shows interest in } \\
\text { food reviews. }\end{array}$ \\
\hline $\mathrm{G}$ & $\begin{array}{l}\text { A } 25 \text {-year-old full-time worker who follows SuhaySalim and TasyaFarasya. Participant G watches their YouTube } \\
\text { videos two or three times a week. She follows them because of the way they speak and how they present } \\
\text { products, which is interesting to watch. }\end{array}$ \\
\hline $\mathrm{H}$ & $\begin{array}{l}\text { A } 24 \text {-year-old company worker who follows FatyaBiya on Instagram and YouTube. Respondent G watches } \\
\text { makeup videos when she needs recommendations on the type of makeup to use. She believes in FatyaBiya's } \\
\text { reviews because her video tutorials are interesting, and reviews all types of makeup that she uses on her tutorials. }\end{array}$ \\
\hline
\end{tabular}




A 25-year-old full-time worker. She is married and often watches videos from Ali Andreea on YouTube and
Instagram because she thinks that Ali Andreea frank and honest. She watches her videos twice a week.
A 29-year-old employer who watches videos from DhanaXaviera on YouTube. She watches some YouTube
tutorials when she wants to learn how to apply makeup because video tutorials are easy to follow.

Appendix 2. Questions for customers/subscribers

\begin{tabular}{|c|c|}
\hline No. & Item \\
\hline 1 & Age \\
\hline 2 & Gender \\
\hline 3 & Status: student / employed / working student \\
\hline 4 & Which beauty creator/YouTubers do you follow? \\
\hline 5 & In which channel do you follow them? (e.g. YouTube, Instagram, Snapchat, Facebook) \\
\hline 6 & How often do you watch YouTubers' video or do you follow them somewhere else in social media? \\
\hline 7 & What got you interested in these YouTubers? \\
\hline \multicolumn{2}{|c|}{ Conception on YouTubers (how do you feel about YouTubers) } \\
\hline 1 & Do you relate to YouTubers? How? \\
\hline 2 & Do you notice YouTubers' marketing and commercialized content? \\
\hline 3 & What kind of marketing and commercialized content have you noticed? \\
\hline 4 & Do you trust YouTubers who recommend products / services? Why? \\
\hline 5 & What do you think about them / commercial collaboration? \\
\hline 6 & Do you believe they recommend products genuinely? \\
\hline \multicolumn{2}{|c|}{ Conception regarding local makeup products } \\
\hline 1 & What do you think about local makeup products? \\
\hline 2 & Have you ever used local products? \\
\hline 3 & How do you make a decision in buying local products? \\
\hline 4 & Did you search for reviews from beauty creators? (e.g YouTube, Instagram, and blogs) \\
\hline \multicolumn{2}{|c|}{ YouTubers' influence on viewers' behavior of buying products } \\
\hline 1 & Does YouTubers' marketing influence you somehow? \\
\hline 2 & Have you bought or wanted to buy products / services like makeup products recommended by a YouTuber? \\
\hline 3 & How much time do you think is needed to make a purchase decision? \\
\hline 4 & How often do you buy products / services recommended by a YouTuber? \\
\hline 5 & If you have bought some products, could you tell me your experience? \\
\hline 6 & Have you noticed YouTubers' influence on your purchase behavior? \\
\hline 7 & Do you have a standard when choosing the YouTubers to follow? \\
\hline \multicolumn{2}{|c|}{ External factor } \\
\hline \multirow{6}{*}{1} & If you have bought products recommended by a YouTuber, in what stage have you experienced their influence? \\
\hline & Need recognition \\
\hline & Information search \\
\hline & Evaluation of alternatives \\
\hline & Purchase \\
\hline & Post purchase behavior \\
\hline 2 & $\begin{array}{l}\text { If you are interested in the content made by certain YouTubers, which factors have affected your buying } \\
\text { behavior? }\end{array}$ \\
\hline 3 & When you watch their video and decide to buy the recommended product, do you need it or want it? \\
\hline 4 & $\begin{array}{l}\text { Is there any external factor (family, friend, and other followers) that exerts an influence on your decision to buy } \\
\text { some products? }\end{array}$ \\
\hline 5 & Does your status have an impact on your buying behavior? How? \\
\hline 6 & $\begin{array}{l}\text { Do you think the values, beliefs, and perceptions you have learned at home influence your buying behavior? How } \\
\text { if there is any? }\end{array}$ \\
\hline \multicolumn{2}{|c|}{ Recommendations of YouTubers } \\
\hline 1 & How do you hope YouTubers would recommend products / services for you? \\
\hline 2 & Which product /service / experience would you like YouTubers to recommend? \\
\hline
\end{tabular}


Appendix 3 Questions for YouTubers

\begin{tabular}{|c|c|}
\hline No. & Items \\
\hline 1 & Age \\
\hline 2 & Gender \\
\hline 3 & Status: student / employed / working student? \\
\hline 4 & Which beauty creator inspired you? \\
\hline 5 & In which channel do you follow them? (e.g. YouTube, Instagram, Snapchat, Facebook) \\
\hline 6 & How often do you make content in your YouTube, Blog, or social media? \\
\hline 7 & What got you interested in making content? \\
\hline 8 & Tell me what you love most about makeup. \\
\hline 9 & Why do you want to share your experience regarding certain products with other people? \\
\hline 10 & Tell me which product you cannot work without. \\
\hline 11 & What is your favorite quote? \\
\hline 12 & What do you think about locally made makeup products? \\
\hline 13 & $\begin{array}{l}\text { What do you think about the portrayal of products through platforms such as YouTube? Do you think they are } \\
\text { effective? }\end{array}$ \\
\hline 14 & Do you think the Indonesian people are getting interested in local products? \\
\hline 15 & What does it feel to be an influencer trying to introduce a local brand? \\
\hline 16 & Do local brands make investment in order to attract customers? \\
\hline 17 & Is there a strategy to attract people to watch your YouTube channel or access it (website, social media)? \\
\hline 18 & How do you choose local products to be introduced on your YouTube channel? \\
\hline 19 & Is there any plan of collaborating with local products in the future? \\
\hline 20 & What is your dream about your blog, and social media? \\
\hline 21 & What is your advice for people who would want to become a social media influencer? \\
\hline
\end{tabular}

\section{Copyrights}

Copyright for this article is retained by the author(s), with first publication rights granted to the journal.

This is an open-access article distributed under the terms and conditions of the Creative Commons Attribution license (http://creativecommons.org/licenses/by/4.0/). 